\title{
The Occurrence of Ochratoxin A in Coffee
}

\author{
I. STUDER-ROHR*, D. R. DIETRICH, J. SCHLATTER $\dagger$ and C. SCHLATTER \\ *Institute of Toxicology, Federal Institute of Technology (ETH) and University of Zürich, Schwerzenbach \\ and + Swiss Federal Office of Public Health, Division of Food Science, Toxicology Section, Schwerzenbach, \\ Switzerland
}

\begin{abstract}
Ochratoxin A (OA) is a nephrotoxic and nephrocarcinogenic mycotoxin which is predominantly produced by the two ubiquitous fungal genera, Aspergillus and Penicillium. OA is found in foodstuffs, predominantly in cereals but also in coffee beans. Inconsistent results have been published regarding the influence of roasting on the $\mathrm{OA}$ content in roasted beans and the transfer into the coffee brew. In the present study an HPLC method was used for the detection of OA in green and roasted coffee beans as well as in the coffee brew. For qualitative confirmation and quantification of low OA levels in roasted coffee beans and coffee brew an additional clean-up step by immunoaffinity column was applied before HPLC analysis. In green coffee beans OA was detected in 13 out of 25 commercial samples analysed (detection limit, $0.5 \mu \mathrm{g} \mathrm{OA} / \mathrm{kg})$. Roasting $\left(250^{\circ} \mathrm{C}, 150 \mathrm{sec}\right)$ of naturally contaminated green beans or beans inoculated with $A$. ochraceus resulted only in a small reduction in the OA level. OA was also found to be eluted into the brew. Of 40 coffee brews prepared from commercially available samples $O A$ was detected in 18 brews by HPLC and/or additional immunoaffinity column clean-up in the range of 0.4 to $7.8 \mu \mathrm{g} \mathrm{OA} / \mathrm{kg}$ equivalent ground coffee. Our preliminary results suggest, therefore, that regular coffee consumption may contribute to exposure of humans to $\mathrm{OA}$.
\end{abstract}

\section{INTRODUCTION}

The mycotoxin ochratoxin $\mathrm{A}(\mathrm{OA})$ derives its name from Aspergillus ochraceus, the first mould from which it was isolated. It is the main toxic component in cultures of this mould, but it is also produced by other ubiquitous moulds such as various other strains of Aspergillus and Penicillium. OA consists of a dihydroisocoumarin moiety linked through its 7-carboxyl group by an amid bond to L-phenylalanine (Fig. 1).

Special attention has been paid to OA since a link between $\mathrm{OA}$ and human Balkan endemic nephropathy (BEN) was postulated (IARC, 1993; Radovanovic, 1989). However, this link has not yet been proven. BEN is a chronic kidney disease predominantly of people living in rural areas of the Balkans (the former Yugoslavia, Romania, Bulgaria). Elevated amounts of OA were found not only in

\footnotetext{
*Author for correspondence at: Institute of Toxicology of the ETH and Uni Zürich, Schorenstrasse 16, CH-8603, Schwerzenbach, Switzerland.

Abbreviations: $\quad$ BEN = Balkan endemic nephropathy; GC-MS = gas chromatography-mass spectrometry; IAC = immunoaffinity column; $\mathrm{NCI} / \mathrm{MID}=$ negative chemical ionization/multiple ion detection; NMR = nuclear magnetic resonance spectrum; NOEL = no-observed-effect level; $O A=$ ochratoxin $A$; $\mathrm{PBS}=$ phosphate buffered saline; $\mathrm{PTWI}=$ provisional tolerable weekly intake; VSD $=$ virtually safe dose.
}

food, but also in the blood sera of people living in the endemic area (Petkova-Bocharova et al., 1988). The human pathology of BEN is a diffuse fibrosis subsequently leading to renal failure. A similar pathology was found in pigs following chronic toxicity studies conducted with OA (Radovanovic, 1989). In all species tested so far (pig, chicken, mouse, rat, dog) $O A$ induced nephrotoxic effects, although the sensitivity of the different species varied (Kuiper-Goodman and Scott, 1989). Ochratoxigenic nephropathy in pigs is a well known and frequently observed disease (Krogh et al., 1976). A disease of poultry related to OA-contaminated feed has also been reported (Harwig et al., 1983). Outbreaks of a similar disease involving the death of a high number of turkeys have been reported in the USA and were causally related to OA-contaminated corn (Harwig et al., 1983).

$\mathrm{OA}$ was also found to be carcinogenic. In two 2-yr carcinogenicity studies with mice and rats, OA was shown to induce kidney tumours (Bendele et al., 1985; Boorman, 1989; IARC, 1993; KuiperGoodman and Scott, 1989). Because of the low doses of $O A$ required to induce tumours in mice and rats, research on $O A$ gained momentum. No genotoxic effect of $O A$ was observed in several genotoxicity test systems (DFG, 1990). However, preliminary experiments have indicated a metabolic activation of $\mathrm{OA}$ by primary cultures of rat hepatocytes resulting in a mutagenic and genotoxic effect (Hennig et al., 1991). 


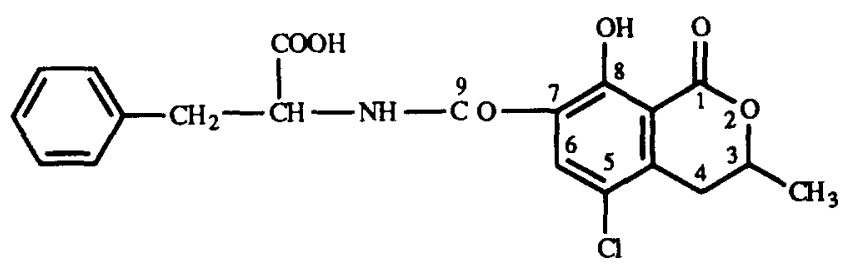

Fig. 1. Chemical structure of ochratoxin A.

Formation of DNA adducts in mouse tissues (kidney, liver, spleen) after administration of a large single oral dose of $2.5 \mathrm{mg} \mathrm{OA} / \mathrm{kg}$ body weight and using the ${ }^{32} \mathbf{P}$ post-labelling method was also observed (PfohlLeszkowicz et al., 1993b). The highest number of adducts $\left(103 / 10^{9}\right.$ nucleotides) were measured in the kidney. In the liver and the spleen the adducts disappeared 5 days after $\mathrm{OA}$ was administered, whereas a small number of adducts $\left(7.7 / 10^{9}\right.$ nucleotides) persisted for at least 16 days in the kidney. DNA adducts were also found in tumourous tissues from three kidneys and five bladders of Bulgarian patients in the range of 11 to 61 adducts $/ 10^{9}$ nucleotides (Pfohl-Leszkowicz et al., 1993a). Of these adducts, several showed the same $R_{\mathrm{F}}$-values as those obtained from mouse kidney after OA treatment. In view of these partially contradictory findings it appeared important to know more about the daily intake of $\mathrm{OA}$ in humans.

OA has been detected in a variety of foods and feeds, mostly from countries with a temperate climate. For humans, the main sources seem to be maize and cereals (DFG, 1990). In a study carried out in Germany with cereals and cereal products about $40 \%$ of the samples contained between 0.1 and $1.5 \mu \mathrm{g} / \mathrm{kg}$ (Rühl et al., 1992). In another study from Germany it was found that $6 \%$ of the cereal samples contained $\mathrm{OA}$ in the range of 0.1 to $17.7 \mu \mathrm{g} / \mathrm{kg}$ (Majerus et al., 1993). In a further study, 56 diffferent beers were analysed (El-Dessouki, 1992). 10 samples were positive $(>0.3 \mu \mathrm{g} /$ litre $)$. Nine of the positive samples were of the Starkbier (strong beer) variety, which is rarely consumed, and contained between 0.35 and $1.53 \mu \mathrm{g} \mathrm{OA} /$ litre. The daily intake of OA was calculated to be about $100 \mathrm{ng}$ (DFG, 1990; Rühl et al.,
1992). OA was also found in about $60 \%$ of more than 500 human blood sera samples [mean of positive samples about $0.8 \mu \mathrm{g} / \mathrm{litre}$, maximum value $14.4 \mu \mathrm{g}$ /litre (DFG, 1990)]. In a recent study in Sweden, 39 human blood samples were analysed. All samples were positive and contained between 0.09 and $0.94 \mu \mathrm{g} \mathrm{OA} /$ litre blood (mean, $0.17 \mu \mathrm{g} /$ litre) (Breitholz-Emanuelsson et al., 1993). These relatively high levels and their high frequency demands further research on OA kinetics in humans and a broader search for other sources of human OA exposure.

$\mathrm{OA}$ has also been detected in green and roasted coffee beans (Cantafora et al,, 1983; Micco et al., 1989; Tsubouchi et al., 1984 and 1988), cocoa beans, soya beans and visibly mouldy peanuts (Harwig et al., 1983). Moreover, OA was found in hazelnuts and dates (Majerus et al., 1993). While only isolated data exist regarding nuts, dates, soya beans and cocoa beans, the natural occurrence of OA in green and roasted coffee beans has been reported several times. However, inconsistent results have been published with respect to the influence of the roasting process on the OA content (Gallaz and Stadler, 1976; Micco et al., 1989; Tsubouchi et al., 1987) and the transfer of OA into the brew (Micco et al., 1989; Tsubouchi et al., 1987).

Because OA has been shown to be a potent carcinogen in animals and it could be present in significant amounts in green and roasted coffee as well as in coffee brew, an HPLC method was adjusted reliably to detect OA without prior derivatization. In the present study the occurrence of $O A$ in green and roasted coffee beans, its destruction by the roasting process and its presence in the coffee brew was investigated. A preliminary estimation of the daily

Table 1. HPLC conditions of System A, used for extracts not purified using the immunoaffinity column

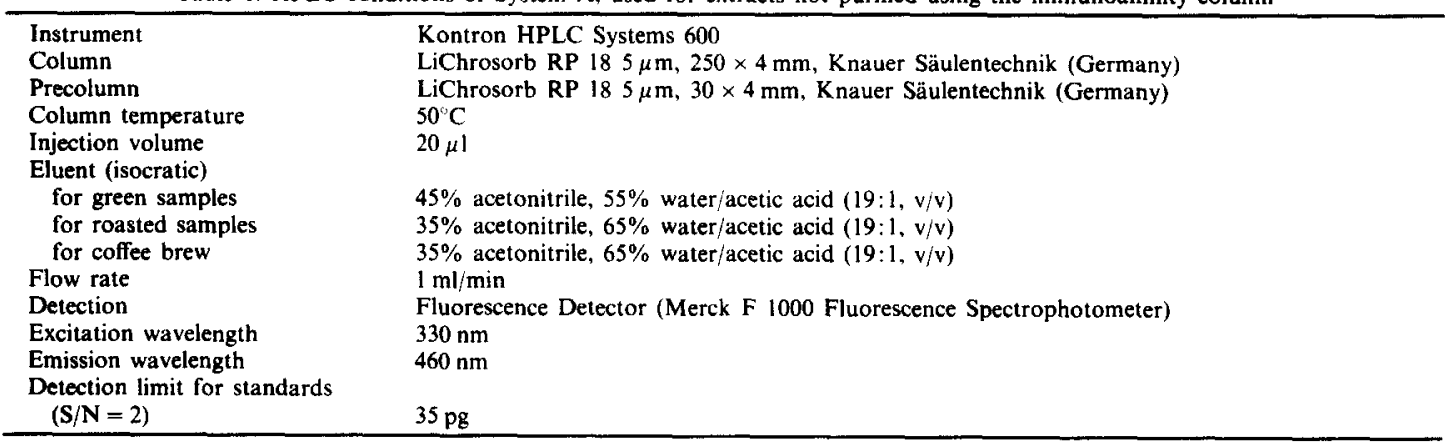


Table 2. HPLC conditions of System B, used for extracts purified using the immunoaffinity column

\begin{tabular}{ll}
\hline Instrument & Kontron HPLC Systems 600 \\
Column & Spherisorb ODS I $5 \mu \mathrm{m}, 250 \times 4 \mathrm{~mm}$, Knauer Säulentechnik (Germany) \\
Precolumn & Spherisorb ODS II $5 \mu \mathrm{m}, 30 \times 4 \mathrm{~mm}$, Knauer Säulentechnik (Germany) \\
Column temperature & $50 \mathrm{C}$ \\
Injection volume & $20 \mu \mathrm{I}$ \\
Eluent (isocratic) & $65 \%$ methanol, $35 \%$ water/acetic acid $(91: 9, \mathrm{v} / \mathrm{v})$ \\
Post-column & \\
$\quad$ alkalinization & $25 \%$ ammonium hydroxide, $0.1 \mathrm{ml} / \mathrm{min}$ \\
Flow rate & $1.0 \mathrm{ml} / \mathrm{min}$ \\
Detection & Fluorescence detector (Merck F 1000 Fluorescence Spectrophotometer) \\
Excitation wavelength & $390 \mathrm{~nm}$ \\
Emission wavelength & $440 \mathrm{~nm}$ \\
Detection limit for standards & \\
$\quad(\mathrm{S} / \mathrm{N}=2)$ & $4 \mathrm{pg}$ \\
\hline
\end{tabular}

human OA intake is given and its possible health risk is discussed.

\section{MATERIALS AND METHODS}

\section{Chemicals}

Ochratoxin $\mathrm{A}$ and phosphate buffered saline (pH 7.4) were purchased from Sigma (St Louis, MO, USA), sodium hydrogen carbonate Art. 6329, methanol p.a. Art. 6009, $n$-hexane puriss. Art. 4360 and formic acid p.a. Art 264 were from Merck (Darmstadt, Germany), celite 545 Art. 22140, isooctane purum Art. 59050, chloroform puriss Art. 25690, hydrochloric acid p.a. Art. 84422 and sodium sulfate anhydrous p.a. Art. 71960 were purchased from Fluka Chemie AG Buchs, Switzerland). Acetonitrile 190 (far UV) was from Romil Chemicals Limited (Loughborough, Leics., UK). Folded filters 595.5 were from Schleicher and Schuell (Kassel, Germany). The immunoaffinity columns were obtained from Biocode Limited (York, UK).

\section{Coffee samples}

25 green coffee samples (weighing between 1 and $5 \mathrm{~kg}$ ) of commercial quality were kindly provided by various coffee companies. Five samples (nos 4, 5, 6, 7 and 8) originated from spoiled coffee lots which were expected to contain high amounts of OA and would not have been marketed. 40 samples of roasted coffee were purchased in different Swiss retail markets.

\section{Green coffee sample treatment}

Each sample of green beans, also to be used for roasting tests, was divided into two parts. One part $(100 \mathrm{~g}-1 \mathrm{~kg})$ was ground with a whole-wheat mill. The other part $(125-500 \mathrm{~g})$ was roasted for $100-190 \mathrm{sec}$ (depending on the sample size) at $252^{\circ} \mathrm{C}$ in a roasting machine (kindly supplied by Tchibo GmbH, Hamburg). For samples which were not roasted $1 \mathrm{~kg}$ was ground. Roasted coffee was ground with a commercial coffee mill. For OA analysis aliquots of $30 \mathrm{~g}$ of ground coffee were used.

\section{Inoculation of green coffee beans}

Two samples of $500 \mathrm{~g}$ green coffee beans (nos 43 and 44) were heat sterilized and inoculated with a spore suspension of Aspergillus ochraceus, according to the method of Gallaz and Stadler (1976). The $A$. ochraceus strain used was IBT/D 738 kindly provided by Dr Jens Frisvad (Copenhagen, Denmark). The inoculated beans were kept at room temperature for $2 \mathrm{wk}$ and then frozen and stored at $-20^{\circ} \mathrm{C}$. Before roasting, the coffee beans were dried for $2 \mathrm{hr}$ at $80^{\circ} \mathrm{C}$ and then treated as described above.

\section{Preparation of the coffee brew}

Coffee was brewed according to the usual Swiss method: $30 \mathrm{~g}$ ground coffee was placed in a commercial paper coffee filter and $500 \mathrm{ml}$ boiling water was poured through the filter. After cooling $300 \mathrm{ml}$ of the brew was taken for analysis.

Table 3. HPLC conditions of System C, used for extracts with and without purification using the immunoaffinity column

\begin{tabular}{lll}
\hline Instrument & Hewlett Packard 1090 Liquid Chromatograph \\
Column & Spherisorb ODS II endcapped, $3 \mu \mathrm{m}, 150 \times 2 \mathrm{~mm}$, Chemie Brunschwig (Germany) \\
Column temperature & $40 \mathrm{C}$ & \\
Injection volume & $5-10 \mu 1$ & Acetonitrile: water/acetic acid (19:1, v/v) \\
Eluent & Time (min) & $30: 70$ \\
& $0-1$ & $80: 20$ \\
& $1-20$ & $80: 20$ \\
& $20-25$ & $30: 70$ \\
& $25-30$ & $30: 70$ \\
Flow rate & post-time 10 min & \\
Detection & $1 \mathrm{ml} / \mathrm{min}$. \\
Excitation wavelength & Fluorescence detector (Hewlett Packard 1046 A) \\
Emission wavelength & $330 \mathrm{~nm}$ & \\
Detection limit for standards & $460 \mathrm{~nm}$ & \\
(S/N $=2)$ & & \\
\hline
\end{tabular}




\section{Chemical analysis}

Green and roasted coffee. The extraction method of Micco et al. (1989) was used, with modifications. An aliquot of $30 \mathrm{~g}$ green or ground roasted coffee was mixed with $60 \mathrm{ml} \mathrm{NaHCO}_{3}(5 \%)$ and $130 \mathrm{ml}$ methanol for $5 \mathrm{~min}$ using a Polytron homogenizer (Polytron PT 3000, Kinematica, Lucerne, Switzerland). The mixture was centrifuged for $20 \mathrm{~min}$ at $3000 \mathrm{~g} .100 \mathrm{ml}$ of the liquid phase (or a lower amount if no derivatization or repeated injections were planned) were transferred into a separatory funnel, defatted with isooctane $(30 \mathrm{ml})$, acidified with concentrated $\mathrm{HCl}(4 \mathrm{ml})$ and extracted with $\mathrm{CHCl}_{3}$ $(1 \times 50 \mathrm{ml}, 1 \times 25 \mathrm{ml})$. The combined chloroform extracts were washed three times with $10 \mathrm{ml} 1.4 \mathrm{M} \mathrm{HCl}$ and dried over anhydrous sodium sulfate. To this final solution, $40 \mathrm{ml} n$-hexane was added and the mixture was then cleaned up by pouring it into a bicarbonate-celite column (previously prepared according to the AOAC, 1984). After washing the column with $50 \mathrm{ml} \mathrm{CHCl}_{3}$ the celite was air-dried. $31 \mathrm{ml}$ chloroform-formic acid $(30 \mathrm{ml}+1 \mathrm{ml})$ was poured into the column, the celite was carefully stirred and the $O A$ was eluted. The column was treated twice with $35 \mathrm{ml}$ chloroform and the combined eluates were evaporated to dryness. The residue was dissolved in $1 \mathrm{ml}$ acetonitrile and the level of $\mathrm{OA}$ was determined at least twice by HPLC analysis. The excitation and emission wavelengths recommended by Bauer et al. (1984) were found to be appropriate. The HPLC conditions (System A) are listed in Table 1.

The detection limits (observation of a distinct signal above background) for green and roasted coffee were $0.5 \mu \mathrm{g}$ and $1.0 \mu \mathrm{g} / \mathrm{kg}$, respectively.

Brew. $150 \mathrm{ml}$ of brew (or a lower amount if less than $1 \mathrm{ml}$ of extract was needed), $2 \mathrm{ml}$ concentrated $\mathrm{HCl}$ and $150 \mathrm{ml}$ chloroform were mixed using a Polytron homogenizer for $5 \mathrm{~min}$. The mixture was centrifuged for $20 \mathrm{~min}$ at $3000 \mathrm{~g}$. Two samples were prepared in this way and the clear chloroform phases $(100 \mathrm{ml}$ each) were combined and $40 \mathrm{ml}$ of $n$-hexane was added. This solution was poured into a bicarbonate-celite column and then analysis continued as described above for green and roasted coffee. The detection limit was $1.0 \mu \mathrm{g} / \mathrm{kg}$ coffee beans (observation of a distinct signal above background).

\section{Confirmation procedures}

Methylation. The method used was originally published by Uchiyama et al. (1985): $200 \mu$ l of the extract ready for HPLC injection was evaporated to dryness and $2.5 \mathrm{ml}$ methanol and $0.1 \mathrm{ml}$ concentrated $\mathrm{HCl}$ were added. The solution was left standing overnight at room temperature. Thereafter the methanol was evaporated and the residue was taken up in $200 \mu 1$ acetonitrile. The HPLC analysis was identical to that described above.

Confirmation through clean-up by immunoaffinity column (IAC). $100 \mu 1$ of extract ready for HPLC was applied to the IAC under addition of $4 \times 5 \mathrm{ml}$ of phosphate buffered saline (PBS) (pH 7.4) containing $15 \%(\mathrm{v} / \mathrm{v})$ methanol and pushed through the column using low pressure $(1-2 \mathrm{ml} / \mathrm{min})$. The column was washed with $10 \mathrm{ml}$ distilled water and air-dried. The PBS/methanol and the water was discarded. OA, now bound in the IAC was then eluted from the column with $3 \mathrm{ml} 100 \%$ methanol. The OA-containing methanol was evaporated in a water-bath $\left(40^{\circ} \mathrm{C}\right)$ under a nitrogen stream. The residue was taken up in $100 \mu 1$ methanol and analysed by HPLC (System B, conditions see Table 2). $50 \mu 1$ of this IAC-purified extract were methylated as described above and analysed again by HPLC (System B).

The immunoaffinity column was regenerated with $20 \mathrm{ml}$ of PBS and was used up to 10 times without decrease of recovery. The recovery from the column with the extract of roasted coffee was $\geqslant 80 \%$. The detection limit was about $0.1 \mu \mathrm{g} / \mathrm{kg}(\mathrm{S} / \mathrm{N} \cong 5)$.

Confirmation of the $O A$ identity through an additional HPLC system. In order to test the selectivity of the IAC and to confirm the identity of OA, an OA standard, and a coffee extract before and after cleaning by IAC were analysed with a third HPLC system, system $C$ (for conditions see Table 3 ). This system was similar to system $\mathrm{A}$, but with a lower detection limit for OA standards.

Table 4. GC and MS conditions

\begin{tabular}{ll} 
& \multicolumn{1}{c}{ Table 4 . GC and MS conditions } \\
\hline & \multicolumn{1}{c}{ GC conditions } \\
Instrument & HRGC $5160 \mathrm{Mega}$ Series, Carlo Erba Instruments \\
Column & $20 \mathrm{~m} \times 0.3 \mathrm{~mm}$ \\
Stationary phase & PS 086 (Polymethylphenylsiloxane containing $12 \%$ phenylgroups) \\
Injection volume & $1-5 \mu 1$ on column (solvent: methanol) \\
Temperature program & $70^{\prime} \mathrm{C}, 1 \mathrm{~min}$ isothermal \\
& $20 \mathrm{C} / \mathrm{min}$ to $250^{\prime \prime} \mathrm{C}$ \\
& $5 \mathrm{C} / \mathrm{min}$ to $320^{\circ} \mathrm{C}$ \\
Elution temperature & $307 \mathrm{C}$ \\
& \\
& \\
Instrument & Finnigan MAT 4510 \\
Ionization mode & Negative chemical ionisation (NCI) \\
Temperature of jon source & $190 \mathrm{C}$ \\
Reagent gas & Methane at 0.6 Torr \\
Registration mode & Multiple ion detection (MID) \\
m/e detected & $416,418,431,433$, cycle time: 1 sec. \\
\hline
\end{tabular}


(a)

2

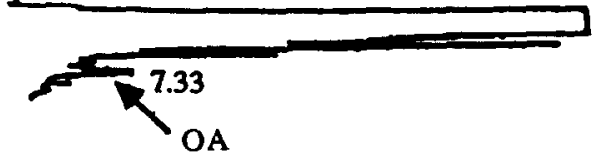

(b)

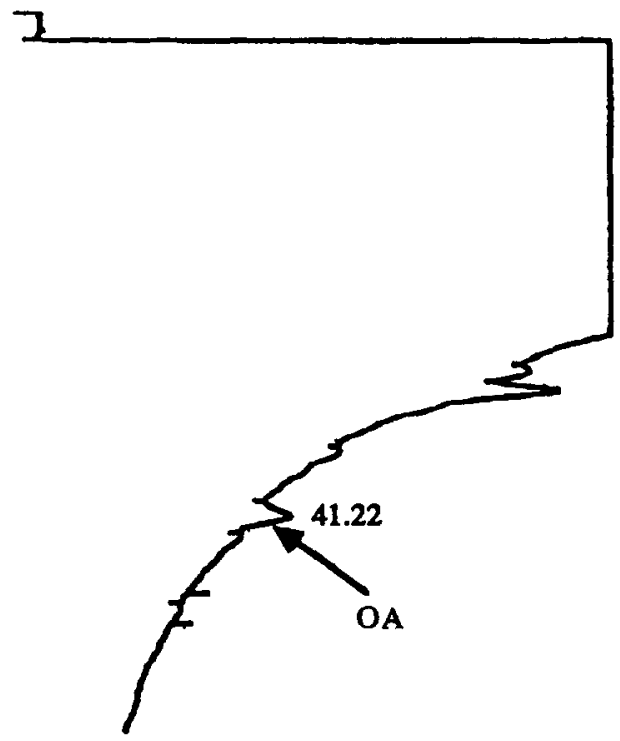

(c)

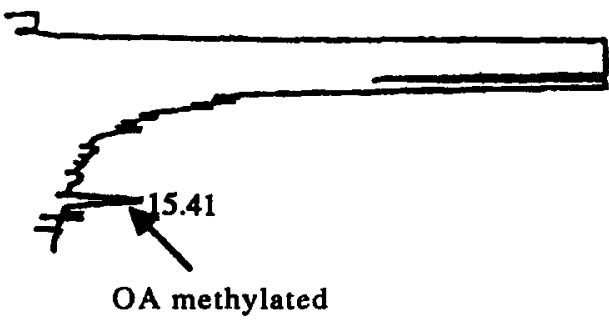

Fig. 2. HPLC chromatograms of (a) green $(2.5 \mu \mathrm{g} \mathrm{OA} / \mathrm{kg}$ ) and (b) ground $(5 \mu \mathrm{g} \mathrm{OA} / \mathrm{kg})$ roasted samples of coffee beans with a low level of $O A$ contamination. The chromatogram of a methylated sample of green beans with $2 \mu \mathrm{g}$ $\mathrm{OA} / \mathrm{kg}$ contamination is shown in (c).

Confirmation by GC-MS. The extract of green coffee, ready for HPLC analysis in system A, was methylated with diazomethane. The extracts of the roasted coffee samples had first to be cleaned up with the IAC and were then methylated with diazomethane. OA was identified and quantified (comparison with a standard solution of methylated $O A$ ) by the NCI/MID (negative chemical ioniz- ation/multiple ion detection) technique with a detection limit of about $0.1 \mu \mathrm{g} / \mathrm{kg}(\mathrm{S} / \mathrm{N} \cong 5)$ for $\mathrm{OA}$ in green and roasted coffee extracts. The GC and MS conditions were as described in Table 4.

\section{Heat stability experiments}

From a standard stock solution of $10 \mu \mathrm{g} \mathrm{OA} / \mathrm{ml}$ ethanol, $500 \mu \mathrm{l}$ was put into each of five small glasses and kept for $0,3,6,9$ or $12 \mathrm{~min}$ at $270^{\circ} \mathrm{C}$. The residues were dissolved in $1 \mathrm{ml}$ acetonitrile and quantified by HPLC.

\section{Calculation of the results}

Comparisons of the $\mathrm{OA}$ levels in green and roasted beans were made on the basis of the weight of green beans. For calculation of OA levels in roasted beans an average loss of $13 \%$ water was assumed during roasting. This value was found in our experiments and corresponds well with those described in the literature (Smith, 1985).

Statistically significant differences of $\mathrm{OA}$ contents between green and roasted beans were calculated with the Mann-Whitney test at $P<0.05$. The maximal percentage of destruction was calculated by a simple regression analysis applying a one-sided confidence limit of $95 \%$.

\section{RESULTS}

\section{Analytical methods}

The analytical method of Micco et al. (1989) was modified in order to be able to measure the OA content of green and roasted coffee without previous derivatization. A typical HPLC chromatogram of a green coffee sample with a low OA content is depicted in Fig. 2a, while a chromatogram of a roasted sample is shown in Fig. $2 b$. The eluent composition used for green coffee, consisting of a $45 \%$ acetonitrile and $55 \% \mathrm{H}_{2} \mathrm{O}$ mix, had to be changed for roasted coffee analysis to a mix of $35 \%$ acetonitrile and $65 \% \mathrm{H}_{2} \mathrm{O}$. Because of the appearance of peaks interfering with the OA peak, a reduction of the organic component was necessary leading to a change in $O A$ retention time. In green beans the retention time of $O A$ was $7.3 \mathrm{~min}$; in roasted beans $\mathrm{OA}$ was detected at $41.2 \mathrm{~min}$. Especially for samples containing only small amounts of OA it is imperative that the HPLC column is in good condition for flawless detection. The condition of the column was checked following 100 injections of roasted coffee or brew samples by injecting the extract of a roasted coffee sample containing a known, small amount ( 1 or $2 \mu \mathrm{g} \mathrm{OA} / \mathrm{kg}$ coffee) of OA. Nevertheless, exact quantification of small amounts $(\leqslant 2-5 \mu \mathrm{g} \mathrm{OA} / \mathrm{kg}$ coffee) was not possible. Thus, the HPLC method (system A) allowed merely semiquantitative assessment of $\mathrm{OA}$ in samples containing OA concentrations near the detection limit.

In order to test the extraction method, three independent recovery experiments per sample type were 


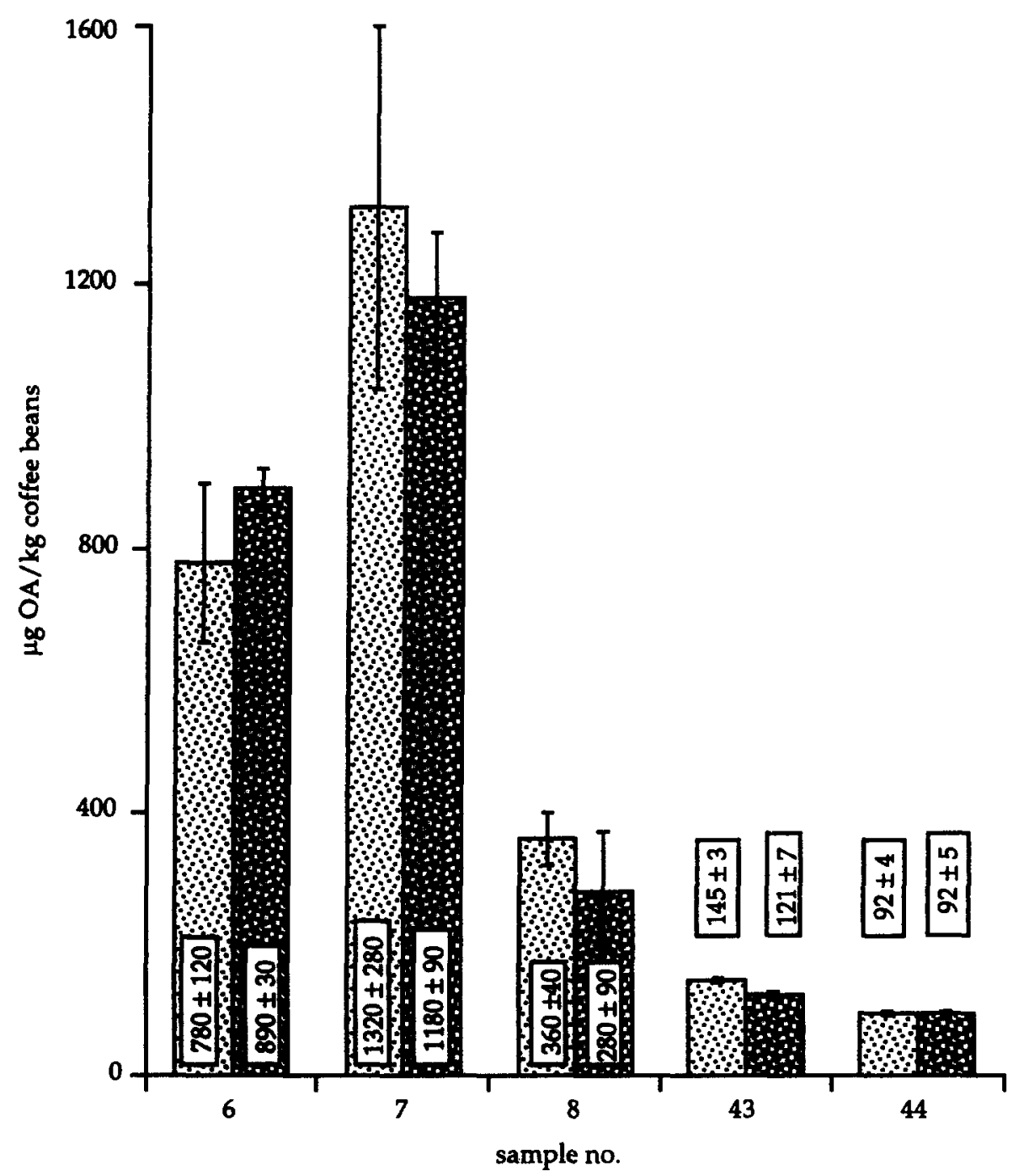

Fig. 3. OA content in naturally contaminated spoiled coffee beans (no. 6,7 and 8) and in artificially inoculated coffee beans (no. 43 and 44) before ( $\mathrm{S}$ ) and after (1) roasting. The $O A$ amounts are calculated based on green bean weight. Arithmetic mean of 3-6 samples \pm standard error of the mean.

carried out with spiked samples. OA recovery in green coffee was $97 \pm 8 \%$ (arithmetic mean $\pm 1 \mathrm{SD}$ ), for roasted coffee $116 \pm 6 \%$ and for the brew $87 \pm 11 \%$. The relatively low' standard deviation indicates a good repeatability of the extraction and analysis method.

Derivatization of OA through methylation of the extracts of several green and roasted coffee samples and brews with subsequent HPLC analysis was used for qualitative confirmation of OA-positive and OAnegative samples. With the derivatization method (Uchiyama et al., 1985) used here approximately $60-80 \%$ of the OA was methylated. A chromatogram of a methylated sample of green coffee beans with low levels of contamination is shown in Fig. 2c. In samples contaminated at a higher level (nos $6,7,8$, 43 and 44; Fig. 3) both the methylated and the unmethylated OA peak could be seen in the chromatogram. In all the 23 samples used for derivatiza- tion the $O A$ results were confirmed. The identity of $O A$ found in green samples was further confirmed by GC-MS (one mouldy and five commercial samples). Fig. 4a shows a total mass spectrum of the methylated standard (10 ng which corresponds to about $500 \mu \mathrm{g} / \mathrm{kg}$ ). OA concentrations above $50 \mu \mathrm{g} / \mathrm{kg}$ could easily be identified and quantified through a total mass spectrum (Jiao et al., 1992). A green sample, containing $300 \mu \mathrm{g} / \mathrm{kg}$ is shown in Fig. $4 \mathrm{~b}$. Low concentrations of OA $(<20 \mu \mathrm{g} / \mathrm{kg})$ were identified and quantified in a multiple ion detection chromatogram as seen in Fig. 4c [(ions 416, 418 (Cl-isotope peak) 431,433 (Cl-isotope peak)]. Furthermore, the identity of $\mathrm{OA}$ in commercial roasted coffee was qualitatively confirmed by GC-MS with two samples (containing 1.5 and $2.0 \mu \mathrm{g} / \mathrm{kg}$ ) after clean-up using an immunoaffinity column. Exact quantification of these samples was not possible due to problems with the GC column. 
The derivatization method with diazomethane could not be used for the confirmation by HPLC because of peaks interfering with the OA peak in the HPLC chromatogram.

In the HPLC chromatograms of highly contaminated roasted samples and the corresponding coffee brews ( $>100 \mu \mathrm{g} \mathrm{OA} / \mathrm{kg}$ ), as well as of the pure heated $O A$, a second peak after the OA peak was observed (Fig. 5). The areas of these peaks ranged between 10 and $30 \%$ of the OA-peak area. In chromatograms of green beans no such peak could be seen. The two peaks were separately methylated and analysed by GC-MS. Practically identical mass spectra and retention times were observed. Therefore there is strong evidence that this peak is a diastereomer of ochratoxin $\mathrm{A}$ formed at elevated temperature. This is also supported by 'H-NMR spectroscopy, which indicates an inversion at the $C(3)$-position of the molecule. So far there is no information available regarding the toxicity of this diastereomer of ochratoxin A.

\section{Analytical results}

The wide range of the OA concentrations found in green coffee (Table 5), emphasizes the general problem that is encountered when working with mycotoxins. The inhomogeneity of the OA contamination within one sample is enormous, due to the fact that often only a few beans within a bag are infested by the mould. This lack of homogeneity necessitates an extraordinarily high number of analyses of aliquots of the same sample in order to quantify the average degree of $O A$ contamination. In highly contaminated samples the OA contamination seemed to be more homogeneous as shown in Fig. 3.

In the naturally contaminated samples (nos 6, 7, and 8; Fig. 3) no statistically significant difference between the OA content of the green and the roasted beans was found. The maximal loss of OA that cannot be detected because of the high standard error of the mean (due to the inhomogeneity of OA distribution) is $14 \%$ for sample $6,45 \%$ for sample 7 and $62 \%$ for sample 8 . Among the two artificially inoculated samples (nos 43 and 44; Fig. 3) that showed a very homogenous contamination no statistically significant $O A$ destruction was seen after roasting in sample no. 44 . The maximal undetectable loss of OA because of roasting would be $13 \%$. However, in sample no. 43 , a statistically significant loss was detected. If the one-sided $95 \%$ confidence limit is applied the loss of OA is estimated to be between 2 and $29 \%$.

In order to investigate the carry-over of $\mathrm{OA}$ from green beans through roasting into the coffee brew (Fig. 6), three selected commercial samples (nos 36, 37 and 38) were analysed. Although the green beans were ground as finely as possible and mixed well before analysis, a certain inhomogeneity remained as it was not possible to grind the green beans finer than semolina. No statistically significant difference between the OA levels of green beans and the coffee brew was detected. The maximal, undetectable loss of OA from green coffee to the brew was 52,67 and $74 \%$ for samples 36, 37 and 38, respectively. However, lower amounts of OA were found in the roasted aliquots than in either the green beans or the brew from the same sample.

To investigate the heat stability, pure OA was kept at similar conditions (time and temperature) as used for roasting (normal roasting conditions for $500 \mathrm{~g}$ coffee are temperatures between 250 and $270^{\circ} \mathrm{C}$ for $120-150 \mathrm{sec})$. This experiment showed clearly that no OA was destroyed during up to $6 \mathrm{~min}$ of heat exposure (Fig. 7) and that a $50 \%$ reduction of the $\mathrm{OA}$ content, mainly due to the epimerization as discussed above, was observed only after $12 \mathrm{~min}$ at $270^{\circ} \mathrm{C}$.

The analysis of 25 green coffee samples obtained from various companies revealed that 13 contained detectable amounts of OA (Table 6). The range of contamination was between 1.2 and $56 \mu \mathrm{g} / \mathrm{kg}$. It must be stated that the sample containing $56 \mu \mathrm{g} / \mathrm{kg}$ had a rather spoiled appearance.

The results of analysis of 40 commercially available roasted samples purchased in various Swiss retail shops are shown in Table 7 . In 21 samples both the brew and the ground coffee were analysed, while for 19 samples only the brew was analysed, since it is the relevant OA source for the consumer. Samples with amounts greater than $2.0 \mu \mathrm{g} / \mathrm{kg}$ were analysed at least twice. Of the 21 analysed ground coffee samples seven were positive, but all except two had amounts near the detection limit (around $1 \mu \mathrm{g} / \mathrm{kg}$ ).

\section{Identification of OA (IAC-HPLC) in roasted samples} with low levels of contamination

To verify the results of the commercial roasted coffee samples and in order to give a more reliable quantification, all positive extracts with amounts of $2 \mu \mathrm{g} / \mathrm{kg}$ or less and four negative extracts were cleaned up using the IAC and again measured by HPLC (system B). OA could be detected in all IAC-cleaned extracts and in addition could be confirmed with methylation (Table 7).

The quantification of the non-methylated and the methylated extracts after IAC cleaning was facilitated by better peak separation and is therefore more reliable. HPLC chromatograms of the same extract of a brew before IAC purification, after IAC purification and the methylated IAC extract are shown in Fig. 8.

In addition, because of the low $k$ value $(k=1.6)$ in the chromatograms of system $B$, one commercial roasted sample $(2 \mu \mathrm{g} / \mathrm{kg})$ was also tested in system $\mathrm{C}$ which is similar to system $A$ (used for the extracts not cleaned up by IAC). The relevant differences from system $A$ were the use of a more powerful fluorescence detector and the use of a narrow-bore HPLC column. This resulted in a five times lower detection limit for $O A$ standard with system $C$ than was achieved previously with system $A$. The $O A$ identity was confirmed by the identical retention time 
$(=18 \mathrm{~min} ; \mathrm{k}=8)$ of the OA standard peak, and the peak in the extracts without and with IAC cleaning.

16 of the 40 analysed brew extracts not cleaned by IAC contained detectable amounts of $\mathrm{OA}(\leqslant 1 \mu \mathrm{g} \mathrm{OA} / \mathrm{kg}$ coffee) and OA levels tended to be higher than those in the ground coffee. This observation corresponds to the results shown in Fig. 6. All of the brew samples with amounts of $2 \mu \mathrm{g}$ or less $\mathrm{OA} / \mathrm{kg}$ ground coffee were confirmed by IAC cleaning including methylation. Also in two brew samples with amounts of OA of $1 \mu \mathrm{g} \mathrm{kg}$ or less in the first HPLC analysis small amounts of OA were detected after IAC cleaning.

In the cases where two or more aliquots of one sample were analysed, again a certain lack of homogeneity of OA contamination could be seen.

\section{DISCUSSION}

The same analytical method was used in this study for the detection of $\mathrm{OA}$ in extracts of green as well as of roasted coffee beans whereas for coffee brew a faster extraction method was applied because of the low fat content: less than $1 \%$ dry weight of solid residues in the brew (Ratnayake et al., 1993) in comparison with a lipid content of between 9 and $20 \%$ in the green and roasted beans (Smith, 1985). Surprisingly, in samples with a relatively low level of contamination we detected significantly lower amounts of $\mathrm{OA}$ in the roasted beans than in the corresponding green beans or brew (samples 36, 37 and 38; Fig. 6). This may be due to incomplete extraction from the roasted beans due to matrix effects (e.g. a limited amount of relatively strong

(a)

rel. Int.<smiles>[Mg][Mg]</smiles>

$M / Z \quad 200$

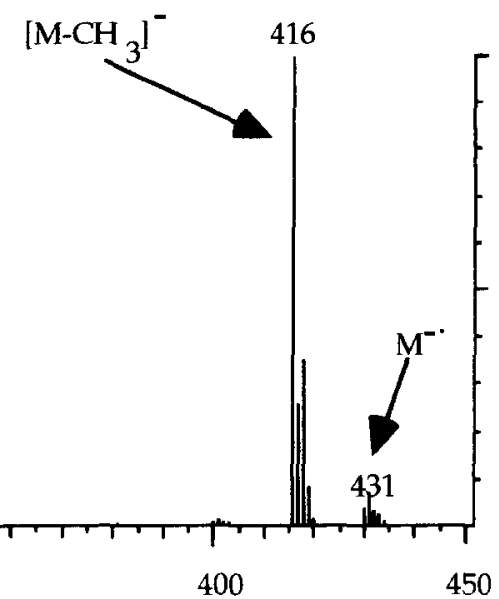

(b)

rel. Int.

100

$-$

$M / Z 200$

250

300

350

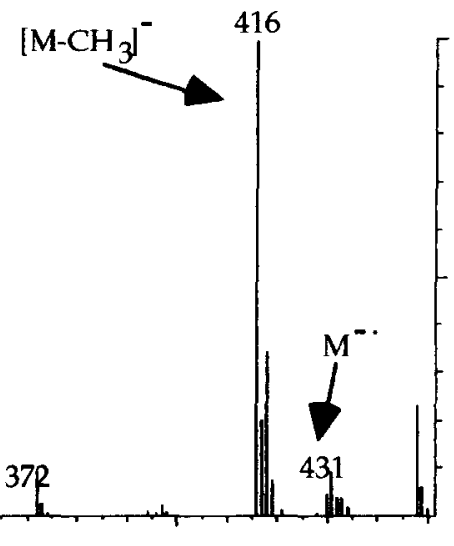

Fig. 4(a,b) (caption opposite) 
(c)

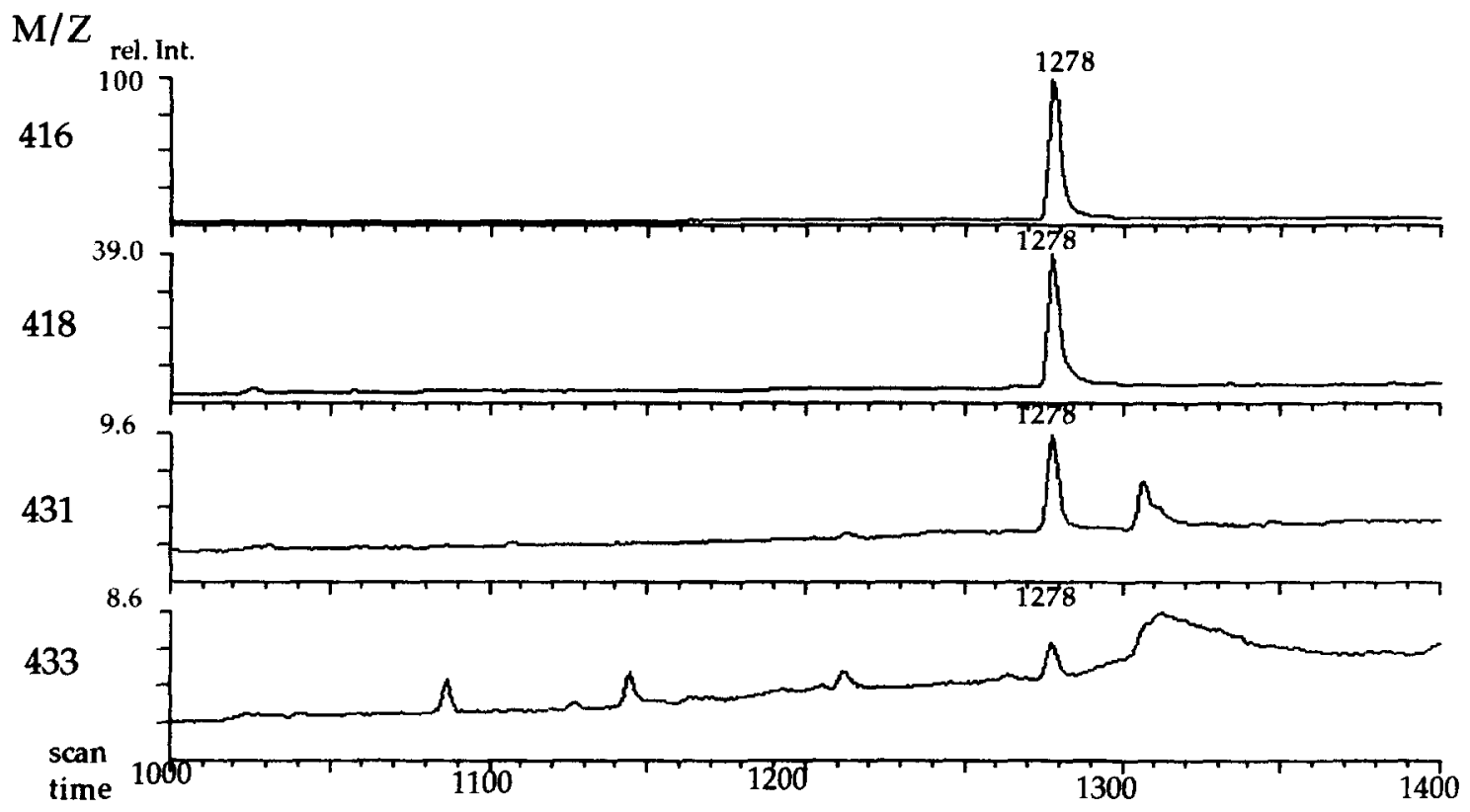

Fig. 4. Total mass spectra of (a) the methylated standard $500 \mu \mathrm{g} \mathrm{OA} / \mathrm{kg}$ and (b) a sample of green coffee beans containing $300 \mu \mathrm{g} \mathrm{OA} / \mathrm{kg}$. (c) A multiple ion detection chromatogram of a sample of coffee beans with $1.5 \mu \mathrm{g} \mathrm{OA} / \mathrm{kg}$.

binding sites, which would influence extractions in the low-level range only). Therefore, the extraction procedure used was not optimal for roasted beans with a low level of OA contamination. Treatment with hot water before extraction, as it is done in coffee brewing, obviously improves the efficiency of OA analysis of roasted coffee, with low levels of contamination.

The lack of baseline separation and the small sample size of roasted samples with low contami-

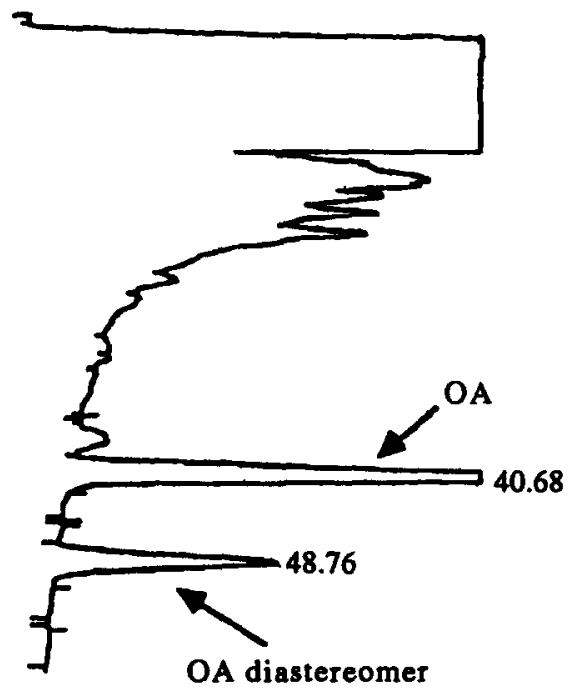

Fig. 5. HPLC chromatogram of a roasted sample with $1500 \mu \mathrm{g} \mathrm{OA} / \mathrm{kg}$ demonstrating the peak of the diastereomer of $\mathrm{OA}$. nation analysed by HPLC system $A$ indicated that a more reliable method of analysis was required. Therefore, to confirm the presence of $\mathrm{OA}$ in commercial roasted samples with little contamination and to get a more reliable quantification, an additional clean-up of the extracts through an immunoaffinity column was applied. This step turned out to be very efficient as shown in Fig. 8. The suspected low OA content could be convincingly confirmed after the additional cleaning step either as native compound or as methylated derivative. Also, the indicated range of contamination after IAC cleaning is reliable. It must still be underlined that even with inclusion of the IAC clean-up the quantification of these results in the range of the detection limit $(0.1-0.5 \mathrm{ppb})$ is only possible within a factor of about 2 .

Table 5. OA in five green coffee samples (analysed without immunoaffinity cleaning): the inhomogeneity of low OA contamination

\begin{tabular}{|c|c|c|c|c|}
\hline \multicolumn{5}{|c|}{ OA $(\mu \mathrm{g} / \mathrm{kg})$ in sample*: } \\
\hline 1 & 2 & 3 & 4 & 5 \\
\hline $\begin{array}{r}<0.5 \\
<0.5 \\
44.0 \\
2.0 \\
3.6\end{array}$ & $\begin{array}{r}<0.5 \\
42.0 \\
7.0 \\
<0.5 \\
<0.5\end{array}$ & $\begin{array}{r}64.0 \\
<0.5 \\
<0.5 \\
1.0 \\
7.3 \\
0.7 \\
<0.5 \\
<0.5 \\
<0.5 \\
<0.5\end{array}$ & $\begin{array}{r}<0.5 \\
<0.5 \\
2.7 \\
1.8 \\
2.5\end{array}$ & $\begin{array}{r}9.1 \\
<0.5 \\
16.0 \\
1.8 \\
2.1\end{array}$ \\
\hline
\end{tabular}

-Individual values of a single analysis. 


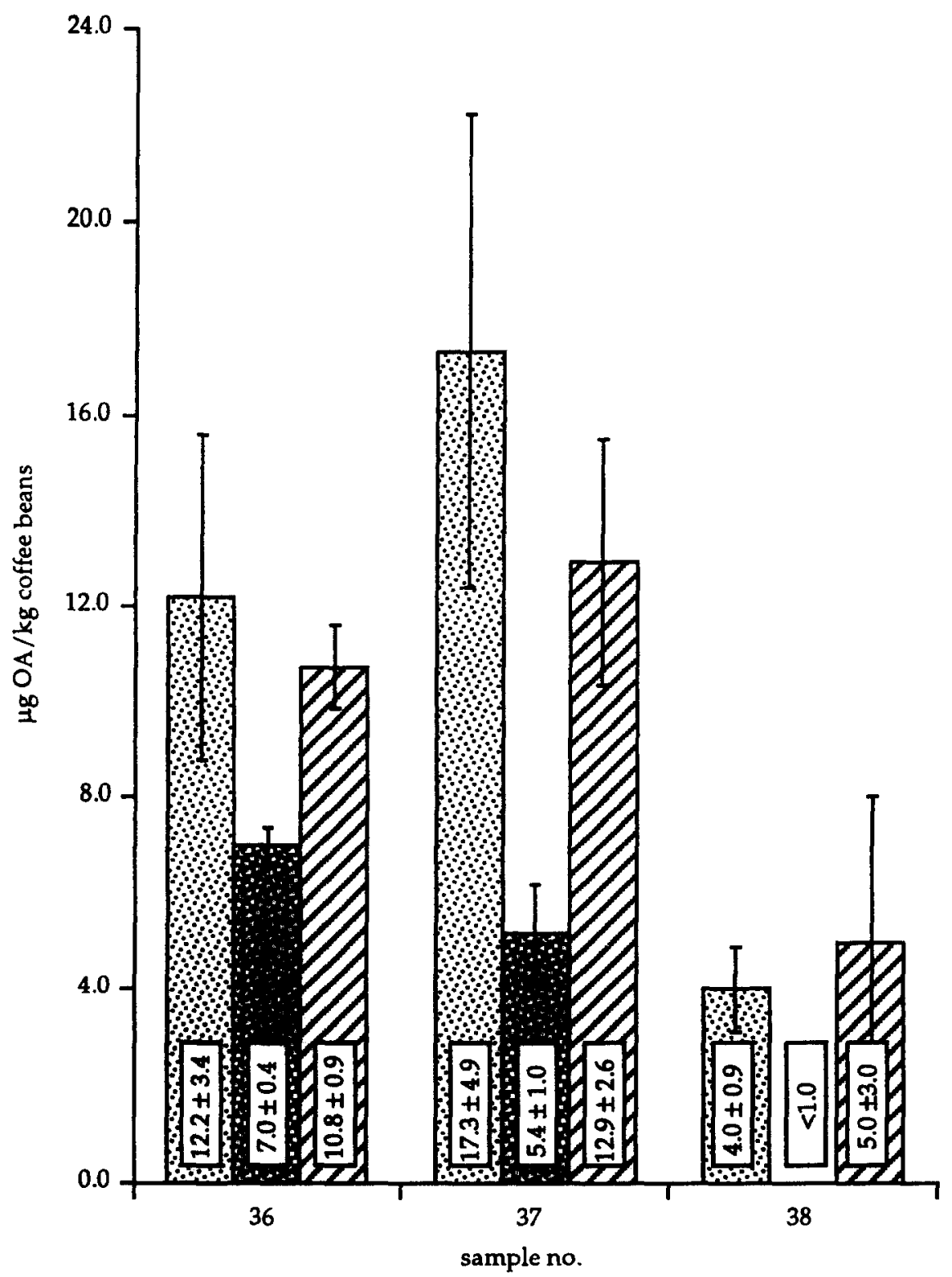

Fig. 6. Carry-over of OA from green beans (W) by roasted beans (B) into the brew ( $\square$ ) of three commercial coffee samples. The $O A$ amounts are calculated based on green bean weight. Arithmetic mean of $4-6$ samples \pm standard error of the mean.

We thus strongly recommend that a clean-up step by IAC is included for analytical studies on low-level $\mathrm{OA}$ contamination in coffee.

Supplementary qualitative confirmations of the $O A$ identity in the extracts were done through GC-MS and through a third HPLC system (system C). All of these analyses showed very clean and unequivocal evidence for the identity of $\mathrm{OA}$ in these IAC cleaned extracts.

The presence of $O A$ in commercial green coffee has been observed by other authors in a similar concentration range as reported here (Table 4). Cantafora et al. (1983) analysed 40 samples of which nine were positive and contained between 0.5 and $23 \mu \mathrm{g} \mathrm{OA} / \mathrm{kg}$,
Tsubouchi et al. (1984) found four positive samples out of 22 (containing $9.9-46 \mu \mathrm{g} / \mathrm{kg}$ ) and Micco et al. (1989) reported that 16 samples out of 29 were contaminated with $\mathrm{OA}$ levels between 0.2 and $15 \mu \mathrm{g} / \mathrm{kg}$.

Because of the inhomogeneity of OA contamination within the coffee samples it is difficult to determine destruction of $\mathrm{OA}$ during roasting when using samples containing only low amounts of $\mathrm{OA}$ (Table 5). Grinding and mixing of the beans could not completely eliminate this problem.

Highly contaminated green beans, where the inhomogeneity was less pronounced, were therefore used for the investigation of $O A$ destruction during 


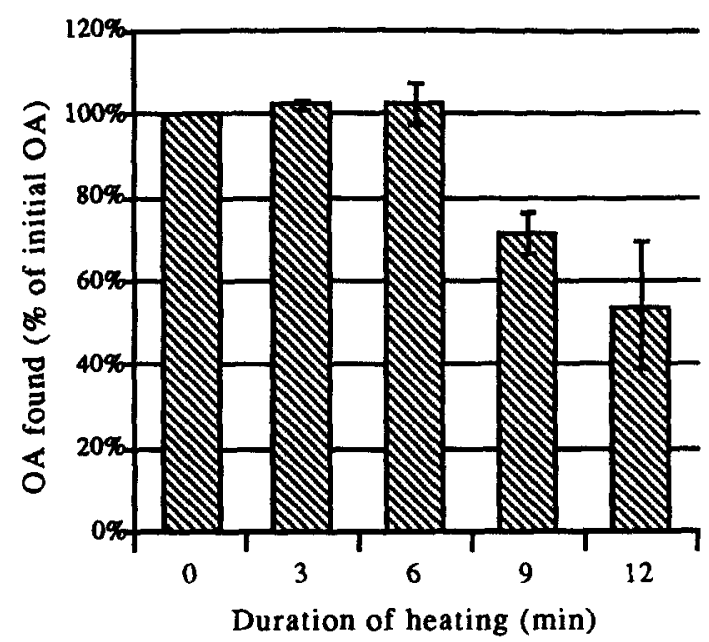

Fig. 7. Heat stability of $O A$ kept for 3,6,9 and 12 min at $270^{\circ} \mathrm{C}$. Arithmetic mean of 4-6 samples \pm standard error of the mean.

roasting. In the three spoiled samples (nos 6, 7 and 8) containing up to $1300 \mu \mathrm{g} / \mathrm{kg}$ (Fig. 3) no statistically significant destruction of $\mathrm{OA}$ could be observed after roasting. However, owing to the lack of homogeneity of the OA content (especially in samples 7 and 8), a loss of OA during roasting of between 14 and $62 \%$ for samples 6,7 and 8 would not have been detected. In the two artificially contaminated samples (nos 43 and 44), OA was very homogeneously distributed, as indicated by the low standard error of the mean. From the results of sample 43 , a statistically significant reduction of $2-29 \%$ of the OA content during roasting is calculated. It is likely therefore that a reduction of the $\mathrm{OA}$ content during roasting of less than $30 \%$ takes place. This calculated small decrease is due partially to some epimerization at $C(3)$, the loss of $O A$ adsorbed on the silver skin, and a possible chemical destruction of $\mathrm{OA}$ by substances in the coffee bean. The results of the heat stability experiment with pure OA solution, which demonstrated that $\mathrm{OA}$ is not detectably destroyed after up to $6 \mathrm{~min}$ of exposure to $270^{\circ} \mathrm{C}$ (which represents a maximum of temperature and double the time normally used for roasting), support our findings of negligible destruction during roasting.

Several studies have been published regarding the heat stability of OA during the roasting process. Tsubouchi et al. (1987) reported a reduction of $0-12 \% \mathrm{OA}$ after roasting artificially inoculated beans contaminated in the range of 200 to $140,000 \mu \mathrm{g} / \mathrm{kg}$, which corroborates our own findings. One can assume a relatively high homogeneity in artificially contaminated samples as indicated by the results presented here, although Tsubouchi et al. (1987) did not report corresponding data.

In all the other studies (Cantafora et al., 1983; Gallaz and Stadler, 1976; Levi et al., 1974; Micco et al., 1989) a destruction of $\mathrm{OA}$ during roasting in the range of between 50 and $100 \%$ was reported. Levi $e t$ al. (1974), Gallaz and Stadler (1976) and Micco et al. (1989) added pure OA directly to the beans in the range of 40 to $350 \mu \mathrm{g} / \mathrm{kg}$. It is very likely that with the loss of the silver skin from the coffee beans during roasting the superficially added $O A$ was also removed. The almost complete destruction of $\mathrm{OA}$ in six mouldy samples containing less than 20-40 $\mu \mathrm{g} \mathrm{OA} / \mathrm{kg}$ found by Gallaz et al. (1976), Cantafora et al. (1983) and Micco et al. (1989) is contradictory to our results. These authors did not take into account problems of inhomogeneity and incomplete extraction in aliquots of samples with low levels of contamination. In addition, they did not compare the content in green beans and in the corresponding brew as we did in our study.

In Fig. 6 it is shown that $O A$ is neither destroyed appreciably by the roasting process, even in the low-level range, nor is it retained in the ground roasted coffee during brewing since the levels found in green coffee beans and in the corresponding brew remained almost the same and no statistically significant difference can be seen. However, the destruction that would have had to take place to detect significant differences between the green coffee and the corresponding brew would have had to be over 52,64 and $74 \%$, respectively, in these experiments. Since the

Table 6. OA levels in 25 commercial green coffee samples received from European suppliers (analysed without immunoaffinity cleaning)

\begin{tabular}{|c|c|c|c|}
\hline Origin and/or type of coffee & $\begin{array}{l}\text { Total no. } \\
\text { samples }\end{array}$ & $\begin{array}{l}\text { Samples positive } \\
\text { at first analysis } \\
(>0.5 \mu \mathrm{g} / \mathrm{kg})\end{array}$ & $\begin{array}{c}\text { OA level in } \\
\text { positive samples } \\
(\mu \mathrm{g} \mathrm{OA} / \mathrm{kg})\end{array}$ \\
\hline Columbia & 5 & 3 & $1.2 ; 9.9 \pm 8.1 * \dagger ; 9.8 \pm 8.4^{*}+$ \\
\hline Santos & 2 & 1 & $7.4 \pm 6.3^{*}+$ \\
\hline Brazil & 3 & 2 & $2.0 ; 4.0 \pm 0.9^{\star}$ \\
\hline Central America & 1 & 0 & \\
\hline Robusta & 3 & 2 & $2.2 ; 3.6$ \\
\hline Ivory Coast & 2 & 2 & $9.9 ; 56.0$ \\
\hline Kenya & 3 & 0 & \\
\hline Guatemala & 1 & 0 & \\
\hline Costa Rica & 1 & 0 & \\
\hline Tanzania & 1 & 1 & 2.2 \\
\hline New Guinea & 1 & 0 & \\
\hline Zaire & 1 & 1 & $17.3 \pm 4.9^{*}$ \\
\hline Unknown & 1 & 1 & $11.8 \pm 3.3^{*}$ \\
\hline
\end{tabular}

*Arithmetic mean ( \pm SEM) of 4-10 samples.

†Individual values are shown in Table 3 (samples 1, 2 and 3). 


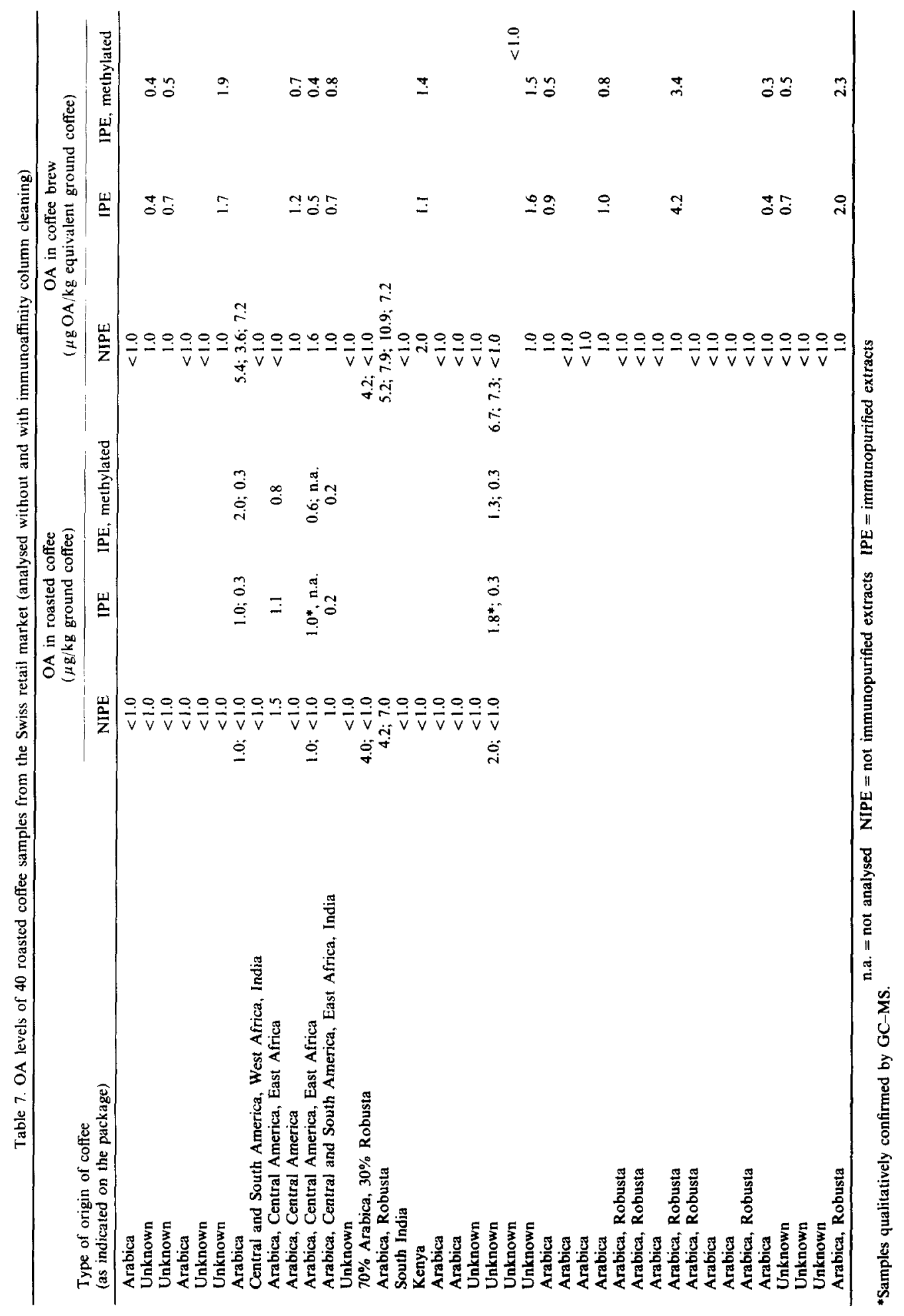


(a)

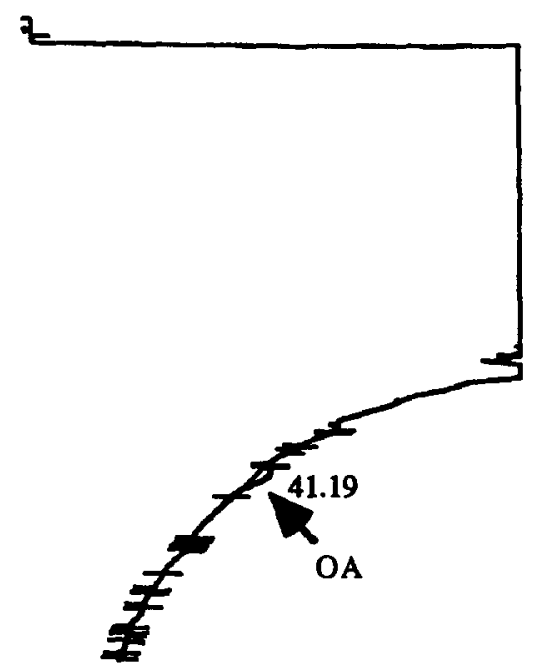

(b)

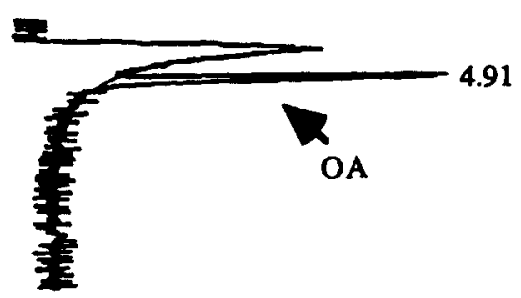

(c)

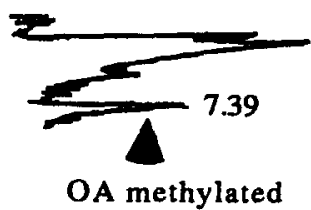

Fig. 8. HPLC chromatograms of same extract of a coffee brew (a) before and (b) after purification on the immunoaffinity column (OA concentration $1 \mu \mathrm{g} / \mathrm{kg}$ ). (c) HPLC chromatogram of the methylated IAC extract.

inhomogeneity in these samples with low levels of contamination is enormous, and only a small number of analyses were carried out, on the basis of these data it can only be stated that more than $25-50 \%$ of the OA detected in green coffee is-after roastingfound in the brew. Indeed, Tsubouchi et al. (1987) reported that $100 \%$ of the $\mathrm{OA}$ detected in roasted coffee could be eluted into the brew, thus corroborating the assumption that a higher percentage $(50 \%$ or more) of $O A$ found in green coffee is transferred into the coffee brew.
Similar data as those discussed earlier for samples 36, 37 and 38 (Fig. 6) concerning the OA level of roasted coffee and the brew were obtained from samples of roasted coffee obtained from Swiss retail market (Table 7). In six samples where OA was detected both in the ground coffee and in the brew, the same or higher OA concentrations were found in the brew (Table 7). The fact that in one sample no OA was detected in the brew, whereas a small amount was found in the ground coffee was probably due to inhomogeneity of OA contamination. This lack of homogeneity is further illustrated with the samples where several aliquots of the same sample were analysed.

OA was also found in commercially roasted beans by Tsubouchi et al. (1988), who reported that five out of $68(7 \%)$ samples purchased in Japan contained OA in the range of 3.2 to $17 \mu \mathrm{g} / \mathrm{kg}$ (detection limit: $2 \mu \mathrm{g} / \mathrm{kg}$ ). The higher percentage of positive samples in our study $(45 \%)$ is due to the lower detection limit $(0.1 \mu \mathrm{g} / \mathrm{kg})$ as only $10 \%$ of the samples in Table $7 \mathrm{had}$ concentrations more than $2 \mu \mathrm{g} / \mathrm{kg}$.

The lower average concentration of $\mathrm{OA}$ in commercially available roasted coffee from the Swiss retail market (Table 7) in comparison with levels in the green samples received from coffee companies (Table 6) is possibly due to the mixture of beans from different origins in the Swiss samples, whereas the green beans were well defined, but surely not representative, samples. Therefore the results shown in Tables 6 and 7 cannot be directly compared.

In order to achieve a more precise estimate of the degree of OA contamination in coffee, as well as to assess the overall contribution of coffee consumption to human OA intake, analyses of a large number of commercial coffee samples should be undertaken.

On the basis of the preliminary results presented here, a daily intake from coffee drinking of about $25 \mathrm{ng} \mathrm{OA}$ per person, corresponding to approximately $0.4 \mathrm{ng} / \mathrm{kg}$ body weight/day is easily possible (based on a daily use of $25 \mathrm{~g}$ ground roasted coffeeabout three or four cups-and a contamination level of $1 \mu \mathrm{g} / \mathrm{kg}$ ). The daily intake of OA through food in general was previously estimated to be about $100 \mathrm{ng}$ (DFG, 1990), corresponding to $1.6 \mathrm{ng} / \mathrm{kg}$ body weight. This indicates that coffee consumption can contribute significantly to the $\mathrm{OA}$ intake of humans. The calculated total daily intake of about $2.0 \mathrm{ng} / \mathrm{kg}$ body weight (from the major sources known so far) is lower than the PTWI (provisional tolerable weekly intake) recommended by the Joint FAO/WHO Expert Committee on Food Additives, 1990 (WHO, 1991) of $112 \mathrm{ng} / \mathrm{kg}$ body weight/wk, corresponding to $16 \mathrm{ng} / \mathrm{kg}$ body weight/day. However, this PTWI accounts for renal damage only and does not take carcinogenicity into consideration.

Regarding carcinogenicity data, Kuiper-Goodman and Scott (1989) calculated a tolerable daily intake of $\mathrm{OA}$ with both a no-observed-effect level (NOEL)/safety factor approach and with a 
mathematical low-dose extrapolation. With an experimentally observed NOEL for tumours at $21 \mu \mathrm{g} / \mathrm{kg}$ body weight/day (Boorman, 1989) and a safety factor of 5000 , the calculated estimated tolerable intake for humans was $4.2 \mathrm{ng} / \mathrm{kg}$ body weight/day. According to the Delaney clause, which was introduced into US legislation in 1958, compounds with carcinogenic properties must not be present in food. This very strict requirement had obviously to be weakened over the past $30 \mathrm{yr}$ when many unavoidable compounds with carcinogenic properties were detected in food. It was therefore agreed in many countries that a theoretical lifetime cancer risk for individual compounds in food of $1: 10^{6}$ (virtually safe dose; VSD) had to be accepted. For OA, the mathematical extrapolation for a lifetime tumour risk of $1: 10^{6}$ resulted in a VSD of $0.2 \mathrm{ng} / \mathrm{kg}$ body weight $/$ day.

At present it is not possible to evaluate fully these theoretical estimates of the carcinogenic risk of human exposure to OA at low dose levels, since the carcinogenic mechanism of OA is not known and no kinetic data for humans are available. If, however, the most conservative approach (as used for the calculation of the VSD) of a linear high to low-dose extrapolation is applied, a cumulative theoretical lifetime risk for a kidney tumour of only $0.0012 \%$ can be calculated from the preliminary data of the total daily OA intake of about $2 \mathrm{ng} / \mathrm{kg}$ body weight. The cumulative lifetime kidney tumour incidence for men and women in Switzerland is 1.3 and $0.6 \%$, respectively (IARC, 1992). This suggests that OA plays only a minor role, if any, among the factors leading to kidney tumours in humans. In addition, one must underline that the linear dose-effect extrapolation for OA carcinogenicity, which is generally only used for genotoxic carcinogens, represents a worst-case scenario and the calculated theoretical risk-which is already small-probably overestimates the real risk. On the other hand, there are profound species differences in OA kinetics (Fuchs, 1988) and it is likely that OA persists longer in humans than in rats. As long as all of these questions have not been solved, and in view of the many different and potent toxic properties of OA, exposure to OA should be kept as low as possible.

Acknowledgements - The authors would like to thank Dr J. Frisvad (Denmark) for supplying the OA-producing fungi strains, Dr P. Schmid for the GC-MS analyses, A.-M. Forss for technical assistance, Dr $\mathrm{O}$. Queckenberg for carrying out the experiments with the HPLC system C, Th. Rásonyi for conducting the experiments concerning the OA diastereomer, and $\mathrm{Dr}$ B. Zimmerli and Dr R. Dick from the BAG in Bern for their helpful advice on the use of the IAC. This work was supported by the International Group on the Physiological Effects of Coffee (PEC).

\section{REFERENCES}

AOAC (1984) Ochratoxins. In Official Methods of Analysis of the Association of Official Analytical Chemists. Edited by S. Williams. 14th Ed. pp. 494-496. Association of Official Analytical Chemists, Arlington, VA.

Bauer J., Gareis M. and Gedek B. (1984) Zum Nachweis und Vorkommen von Ochratoxin $A$ bei Schlachtschweinen. Berliner und Münchner Tierärztliche Wochenschrift 97, 279-283.

Bendele A. M., Carlton W. W., Krogh E. B. and Lillehoj E. B. (1985) Ochratoxin A carcinogenesis in the (C57BL/\&J $\left.\mathrm{X} \mathrm{C}^{*} \mathrm{H}\right) \mathrm{F}_{1}$ mouse. Journal of the National Cancer Institute 75, 733-742.

Boorman G. A. (1989) Toxicology and Carcinogenesis Studies of Ochratoxin A in F344/N Rats. NTP Technical Report no. 358.

Breitholz-Emanuelsson A., Olsen M., Oskarsson A., Palminger I. and Hult K. (1993) Ochratoxin A in cow's milk and in human milk with the corresponding human blood samples. Journal of the Association of Official Analytical Chemists 76, 842-846.

Cantafora A., Grossi M., Miraglia M. and Benelli L. (1983) Determination of ochratoxin $A$ in coffee beans using reversed-phase high performance liquid chromatography. La Rivista della Societa di Scienza dell' Alimentazione 12, 103-108.

DFG (1990) Ochratoxin A, Vorkommen und toxikologische Bewertung. Deutsche Forschungsgemeinschaft, DFG.

El-Dessouki S. (1992) Ochratoxin A in Bier. Deutsche Lebensmittel-Rundschau 88, 354-355.

Fuchs R. (1988) Distribution and Fate of Ochratoxin A in Experimental Animals. Doctoral Thesis, Uppsala, Sweden.

Gallaz L. and Stadler R. (1976) Ochratoxin A im Kaffee Chemie, Mikrobiologie, Technologie der Lebensmittel 4, 147-149.

Harwig J., Kuiper-Goodman T. and Scott P. M. (1983) Microbial food toxicants: ochratoxins. In CRC Handbook of Foodborne Diseases of Biological Origin. Edited by M. J. Rechcigl. pp. 193-238. CRC Press, FL.

Hennig A., Fink-Gremmels J. and Leistner L. (1991) Mutagenicity and effects of ochratoxin $A$ on the frequency of sister chromatid exchange after metabolic activation. In Mycotoxins, Endemic Nephropathy and Urinary Tract Tumours. Edited by M. Castegnaro, R. Plestina, G. Dirheimer, I. N. Chernozemsky and H. Bartsch. IARC Scientific Publications no. 115. pp. 255-260. International Agency for Research on Cancer, Lyon.

IARC (1992) Cancer Incidences in Five Continents. Edited by D. M. Parkin, C. S. Muir, S. L. Whelan, Y.-T. Gao, J. Ferlay and J. Powell. IARC Scientific Publications no. 120. pp. 767-769. International Association of Cancer Registries, Lyon.

IARC (1993) Ochratoxin A. IARC Monographs on the Evaluation of Carcinogenic Risks to Humans. Vol. 56. Some Naturally Occurring Substances: Food Items and Constituents, Heterocyclic Aromatic Amines and Mycotoxins. pp. 489-521. International Agency for Research on Cancer, Lyon.

Jiao Y., Blaas W., Rühl C. and Weber R. (1992) Identification of ochratoxin A in food samples by chemical derivatization and gas chromatography-mass spectrometry. Journal of Chromatography 595, 364-367.

Krogh P., Elling F., Gyrd-Hansen N., Hald B., Larsen A. E., Lillehoj E. B., Madsen A., Mortensen H. P. and Ravnskov U. (1976) Experimental porcine nephropathy: changes of renal function and structure perorally induced by crystalline ochratoxin A. Acta Pathologica Microbiologica Scandinavica Section A 84, 429-434.

Kuiper-Goodman T. and Scott P. M. (1989) Risk assessment of the mycotoxin ochratoxin A. Biomedical and Environmental Sciences 2, 179-248.

Levi C. P., Trenk H. L. and Mohr H. K. (1974) Study of the occurrence of ochratoxin $A$ in green coffee beans. Journal of the Association of Official Analytical Chemists 57, 866-870. 
Majerus P., Cutka I., Dreyer A., El-Dessouki S., Eyrich W., Reusch H., Schurer B. and Waiblinger H. U. (1993) Zur Belastungssituation von Ochratoxin $A$ in Lebensmitteln pflanzlichen Ursprungs. Deutsche Lebensmittel-Rundschau 89, 112-114.

Micco C., Grossi M., Miragli M. and Brera C. (1989) A study of the contamination by ochratoxin $\mathrm{A}$ of green and roasted coffee beans. Food Additives and Contaminants 6, 333-339.

Petkova-Bocharova T., Chernozemsky I. N. and Castegnaro $M$. (1988) Ochratoxin A in human blood in relation to Balkan endemic nephropathy and urinary systems tumours in Bulgaria. Food Additives and Contaminants 5, 299-301.

Pfohl-Leszkowicz A., Grosse Y., Castegnaro M., Nicolov I. G., Chernozemsky I. N., Bartsch H., Betbeder A. M., Creppy E. E. and Dirheimer G. (1993a) Ochratoxin A-related DNA adducts in urinary tract tumours of Bulgarian subjects. In Postlabelling Methods for Detection of DNA Adducts. Edited by E. H. Phillips, M. Castegnaro and H. Bartsch. IARC Scientific Publications no. 124. pp. 141-148. International Agency for Research on Cancer, Lyon.

Pfohl-Leszkowicz A., Grosse Y., Kane A., Creppy E. E. and Dirheimer G. (1993b) Differential DNA adduct formation and disappearance in three mouse tissues after treatment with the mycotoxin ochratoxin A. Mutation Research 289, 265-273.

Radovanovic Z. (1989) Aetiology of Balkan nephropathy: a reapprisal after 30 years. European Journal of Epidemiology $5,372-377$.
Ratnayake W. M. N., Hollywood R., O'Grady E. and Stavric B. (1993) Lipid content and composition of coffee brews prepared by different methods. Food and Chemical Toxicology 31, 263-269.

Rühl C., Weber R. and Jiao Y. (1992) Ochratoxin A Aufnahme mit Cerealien. Tätigkeitsbericht Bundesgesundheitsamt 1991. pp. 214-215.

Smith A. W. (1985) Introduction. In Coffee: Chemistry. Edited by R. J. Clarke and R. Macrae. pp. 1-41. Elsevier, London.

Tsubouchi H., Terada H., Yamamoto K., Hisada K. and Sakabe Y. (1988) Ochratoxin A found in commercial roast coffee. Journal of Agricultural and Food Chemistry 36, 540-542.

Tsubouchi H., Yamamoto K., Hisada K. and Sakabe Y. (1984) A survey of occurrence of mycotoxins and toxigenic fungi in imported green coffee beans. Proceedings of the Japanese Association of Mycotoxicology 19, 14-21.

Tsubouchi H., Yamamoto K., Hisada K., Sakabe Y. and Udagawa S. (1987) Effect of roasting on ochratoxin A level in green coffee beans inoculated with Aspergillus ochraceus. Mycopathologia 97, 111-115.

Uchiyama S., Saito Y. and Uchiyama M. (1985) Proteinbinding of ochratoxin $A$ and its extractability from proteinous food. Journal of the Food Hygiene Society of Japan 26, 651-657.

WHO (1991) Evaluation of certain food additives and contaminants. WHO Technical Report Series, 37th Report of the Joint FAO/WHO Expert Committee on Food Additives. WHO Technical Report Series no. 806, pp. 29-31. 